\title{
Research on Dujiangyan Global Tourism Public Service Based on Tourist Satisfaction
}

\author{
Pei Wang ${ }^{1}$ \\ ${ }^{1}$ School of Public Administration, Southwest Jiaotong University, Chengdu, Sichuan, 610031, China \\ *Corresponding author. Email: 2395075942@qq.com
}

\begin{abstract}
This research aims to do the research on Dujiangyan's global tourism public service for the first time, and designs a brand-new service evaluation index system, including travel convenience and benefit services, tourist rights protection services, tourism public safety services, tourism public convenient transportation services, and tourism public information services. And from the perspective of satisfaction, through questionnaires, interviews and other methods to understand tourists' view on the five aspects of services above, it is concluded that tourists' overall evaluation of Dujiangyan's global tourism public services is between general and satisfaction. Tourism public information services earns the most score while tourism public security services scores least. This article also explores the relationship between the overall evaluation of its tourism public service and the evaluation of each subsystem by using multiple linear regression. Finally, in response to the problems reflected in the evaluation results, this article proposes to take some measures, such as increasing the development of scenic spots, building smart tourism, improving public transportation services, improving the public safety service system, and strengthening the protection of tourists' rights and interests, so as to improve the quality of service and improve tourist satisfaction.
\end{abstract}

Keywords: Global tourism, Tourism public service, Global tourism public service evaluation index system, Multiple linear regression, Countermeasures and suggestions.

\section{INTRODUCTION}

In 2016, global tourism was proposed and implemented as a tourism development strategy in the new era. In March 2018, the relevant departments of the State Council issued the "Guiding Opinions on Promoting the Development of Global Tourism", highlighting the task of "strengthening basic facilities and improving public services", and clarified that the quality of tourism public services plays a important role in the development of global tourism. The Ministry of Culture and Tourism of the People's Republic of China also issued the "Guiding Opinions of the Ministry of Culture and Tourism on the Implementation of the Tourism Service Quality Improvement Plan" in 2019, which pointed out that in order to promote the development of higher-quality tourism in the whole region, it is necessary to find and solve the problems that affect the tourist experience. To judge the level of global tourism development, the quality of tourism public services is an important factor that cannot be ignored. Therefore, research on tourism public services has important practical significance to promote better development of global tourism.

In 2016, Dujiangyan City was selected as one of the first batch of "National Tourism Demonstration Zones", under the situation of vigorously promoting the development of global tourism, how to better satisfy tourists' satisfaction with tourism services and improve the quality and level of the supply of various tourism public services is one of the important issues that Dujiangyan City needs to consider in the development of global tourism. In this context, this research is of great significance to the improvement of Dujiangyan's global tourism public services, enhancement of tourist satisfaction, and promotion of the development of Dujiangyan's tourism industry.

\section{RELATED CONCEPTS AND LITERATURE REVIEW}

\subsection{Definition of Global Tourism}

Although global tourism was proposed as a brandnew tourism concept in my country in 2016, and a 
unified concept has not yet been formed, some scholars have given their own definitions of global tourism.

Hou Xiaomin (2017) believes that global tourism is the delineation of a specific area, and the tourism development of the place is regarded as one of the important indicators, and the relevant elements such as the tourism environment and tourism services are recombined or improved [6]. The government takes the initiative to play its role in comprehensive regulation. Improve the tourist quality of tourists, form a highquality living environment, and promote new tourism development models. Li Huajun (2020) also advocates the soundness and improvement of the tourism public service system, and believes that global tourism needs to meet people's tourism needs from the "full process, full time and space, and all aspects", and firmly grasp the current tourism trends to bring tourists Come for a better travel experience[10].

Therefore, global tourism is inseparable from the construction of tourism public services. From the perspective of global tourism, tourism public services are required to be high-quality, convenient and full coverage, which can improve the quality of public services and better meet the diverse needs of tourists. , To improve the satisfaction of tourists.

\subsection{Research Summary of Tourism Public Service}

\subsubsection{The Connotation and Objects of Tourism Public Service}

Li Shuang et al. (2012) believe that tourism public services refer to: "The general term for products and services that are provided by the government or other social organizations to meet the common needs of tourists, not for profit, and have obvious publicity"[18]. Any public service has a designated service object, and tourism public service is no exception. There are specific beneficiaries, and there are broad and narrow senses according to the scope of benefit. The narrow sense mainly refers to tourists, including existing and potential tourists; and the broad service targets include not only tourists, but also governments, tourism companies, and local communities. This research mainly focuses on tourists for the service objects of tourism public services to carry out investigations.

\subsubsection{The Composition (Content) of Tourism Public Services}

Hou Xiaomin (2017) advocated that the global tourism public service evaluation system includes: tourism information consulting system, travel convenient transportation system, tourism safety guarantee system, tourism convenience and benefit system, tourism administrative service system [6]; Chen
Yizi (2019) pointed out that the global tourism public The service system includes tourism convenience services, tourism public safety services, tourist rights protection, tourism public transportation networks, and smart tourism services [5]. Li Huajun (2020) believes that the content of global tourism public services should include public transportation services, public information services, public safety services, administrative management services, and services that benefit the people and the people [10].

Therefore, based on the existing research results of predecessors, combined with the actual situation of Dujiangyan tourism, find out the main content of its tourism public services, and construct the evaluation index system of Dujiangyan's global tourism public services, so as to evaluate the quality of tourism public services for tourists Provide a basis for satisfaction.

\subsubsection{Evaluation of Tourism Public Services}

Satisfying the needs of tourists is the ultimate goal of providing tourism public services. Therefore, the evaluation of tourism public services is particularly important. The most important manifestation is the satisfaction of tourists with tourism public services. For this reason, many domestic scholars have conducted research on satisfaction. For example, Xiao Tingting et al. (2011) used factor analysis to evaluate the satisfaction of the Guilin Tourism Reform Pilot Zone [16]; another example is Li Huajun (2020) Using IPA analysis method and based on tourist satisfaction, the whole area tourism public service of Wuyi Mountain is analyzed [10]. From the perspective of tourist satisfaction, "quantification + case" is the main feature of tourism public service quality evaluation and satisfaction research, and scholars basically start from a narrow scope, and regard tourists as the main body of tourism public service quality evaluation (Xu Fuying, Liu Tao 2020) [8].

Based on the perspective of the satisfaction of local residents and foreign tourists, this article evaluates Dujiangyan's public tourism services, I hope that some problems can be discovered from it, and further improvements can be made to better meet the diverse needs of tourists.

\subsection{Literature Review}

Through extensive review of relevant literature, the author found that although the current research on tourism public services is relatively mature, there are not many literatures on tourism public services from the perspective of global tourism, so it is a topic worthy of in-depth research in recent years; Secondly, the literature on the public service of Dujiangyan global tourism as the main body of research is almost blank, so this article has a certain degree of innovation; finally, as 
a demonstration area of national global tourism, Dujiangyan has done a good job in this regard in recent years. However, it is not without problems. Therefore, this article takes the needs of tourists as the starting point and adheres to the people-oriented concept. By investigating tourists' satisfaction with Dujiangyan's tourism public services, it has found its shortcomings, and then put forward targeted suggestions for improvement.

\section{RESEARCH DESIGN}

\subsection{Construction of Dujiangyan Global Tourism Public Service Evaluation Index System}

At present, the academic circles have done some research on the composition of the tourism public service evaluation index system, but under different research perspectives, the composition will be different for different research objects. This article analyzes the basis of the previous research results The above, mainly draws on the research results of scholars such as Hou Xiaomin (2017), Chen Yizi (2019), and Li Huajun (2020) on global tourism, combined with the development status of global tourism in Dujiangyan City, and designed as shown in Table 1 under the perspective of global tourism The public service evaluation index system of China, the system mainly includes five aspects, including tourism benefits and convenience services, tourist rights protection, public safety services, public convenient transportation services, and public information services, with a total of 27 indicators. And on the basis of this indicator system, a questionnaire design and survey were carried out.

Table 1. Dujiangyan City's global tourism public service evaluation index system

\begin{tabular}{|c|c|c|}
\hline Target layer & Criterion layer & Index layer \\
\hline \multirow{18}{*}{$\begin{array}{l}\text { Global } \\
\text { Tourism } \\
\text { Public Service } \\
\text { Evaluation }\end{array}$} & \multirow{5}{*}{$\begin{array}{l}\text { Tourism public } \\
\text { information service }\end{array}$} & Complete Tourist Information Service Center \\
\hline & & Tourist call center in time \\
\hline & & Complete systems such as travel guide signs \\
\hline & & Comprehensive travel advisory website \\
\hline & & $\begin{array}{l}\text { Well-developed AI (artificial intelligence) and VR (virtual } \\
\text { reality) services }\end{array}$ \\
\hline & \multirow{6}{*}{$\begin{array}{l}\text { Travel convenience } \\
\text { and benefit services }\end{array}$} & Scenic toilets are convenient and sanitary \\
\hline & & $\begin{array}{l}\text { Complete convenience facilities (communication, finance, } \\
\text { barrier-free facilities, etc.) }\end{array}$ \\
\hline & & Perfect public rest area \\
\hline & & Tourism benefits policy \\
\hline & & Perfect tourism volunteer service system \\
\hline & & Supply of convenient shared equipment \\
\hline & \multirow{7}{*}{$\begin{array}{l}\text { Tourism public } \\
\text { security service }\end{array}$} & Safety notification forecast is timely and accurate \\
\hline & & The alarm call is unblocked and timely \\
\hline & & Sound medical assistance \\
\hline & & Convenience of accident insurance purchase \\
\hline & & Complete emergency rescue facilities \\
\hline & & Food safety in scenic spots and surrounding catering \\
\hline & & $\begin{array}{l}\text { The people in the tourist area are honest and the society is } \\
\text { in good order }\end{array}$ \\
\hline
\end{tabular}




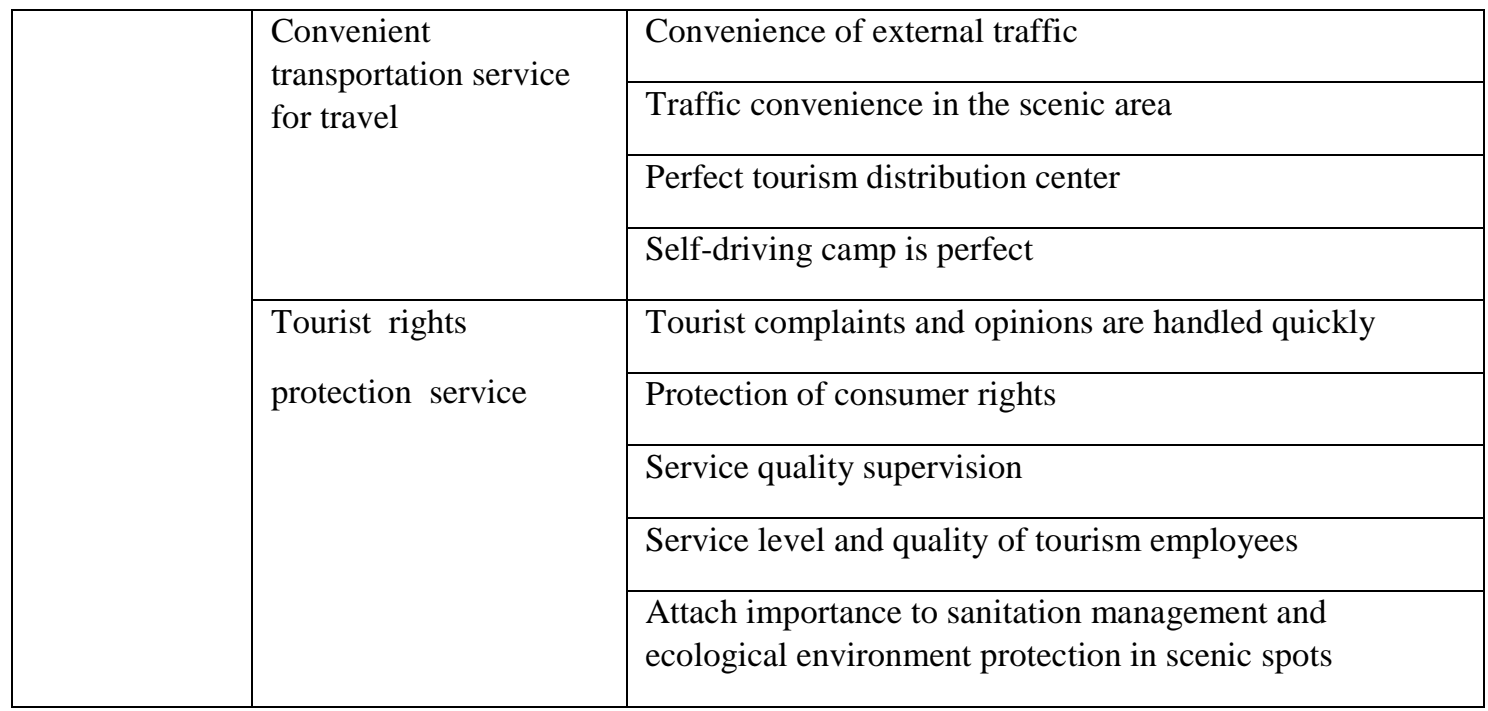

\subsection{Design of the Questionnaire}

The questionnaire design in this article mainly uses the Likert scale for research. The Likert scale assigns 15 points, which represent very satisfied, satisfied, average, dissatisfied, and extremely dissatisfied (detailed questionnaire design can be seen in Appendix 1). The survey subjects selected in this study are mainly tourists and friends who have been to Dujiangyan, as well as local residents of Dujiangyan. Questionnaires were distributed online and offline, and several popular attractions in Dujiangyan were selected offline, such as Dujiangyan Water Conservancy Project, Qingcheng Mountain, and Guan Popular scenic spots such as the ancient city of the county and the Hongkou scenic spot conducted questionnaires and simple interviews with tourists and friends. The offline survey time was concentrated on the three days of January 2, 3, and 4, 2021. Due to time constraints, this study also adopted the form of online questionnaires to collect data more conveniently and efficiently for sorting and analysis.

\subsection{Basic Data Analysis}

In this survey, a total of 150 questionnaires were distributed and 125 valid questionnaires were returned, accounting for $83.3 \%$ of valid questionnaires. The Cronbach's $\alpha$ coefficient of the questionnaire is 0.891 , indicating that the questionnaire is highly reliable.

In terms of age structure, the proportions of 18-25 years old and 26-35 years old are $40 \%$ and $36 \%$ respectively, and both account for $76 \%$ of the total sample, indicating that young people love travel more and are more interested in travel methods and services. There are higher and more modern demands.

In terms of occupation, in addition to students, more than $40 \%$ have stable jobs. In terms of monthly income, more than $60 \%$ of tourists earn more than 3,000 yuan. It also reflects that the current tourists in Dujiangyan have relatively stable economic sources and spending power, so attention should be paid to the protection of tourists' consumption rights.

In terms of tourist source distribution, $79 \%$ of tourists come from within Chengdu and Sichuan Province, indicating that the scope of this tourism promotion is relatively small and lacks sufficient attraction for tourists from other provinces.

In terms of travel methods, mainly self-guided tours and self-driving tours, accounting for $36 \%$ and $24 \%$, respectively, are the prevailing travel methods in the context of global tourism, and their requirements for the quality and standard of tourism public services are also higher.

In summary, the data reflected by tourists on indicators such as age, occupation, source distribution, travel mode, etc. show that tourists' demand for tourism public services is diversified and different.

\section{ANALYSIS OF EVALUATION RESULTS OF TOURISM PUBLIC SERVICES}

\subsection{Overall Evaluation}

According to the survey results, tourists' overall satisfaction with Dujiangyan tourism public services has an average score of 3.6 and a mode of 4 . In other words, the overall satisfaction evaluation of tourists is between general and satisfaction, and satisfaction is slightly inclined to satisfaction; in terms of perception evaluation of the five subsystems, the highest score is tourism public information service (3.8), and the lowest score It is a tourism public safety service (3.43). In interviews and surveys, it is found that most tourists are satisfied with the information services provided by Dujiangyan's Tourist Service Center and tourism-related websites, such as introduction to attractions, tourism 
signs, and ticket reservations. The lowest score is tourism public security services, which may be related to the fact that tourists rarely have the opportunity to directly access these aspects of services; the overall evaluation of other subsystems is relatively close, indicating that tourists have a certain degree of understanding of all aspects

\subsection{Respective Evaluation of Five Aspects}

In terms of tourism public information services, the comprehensive evaluation of tourists is satisfactory. At present, the public information service system of Dujiangyan is relatively complete. For example, the official website of Dujiangyan Tourism has been established, from the facts of the scenic spot, ticket booking, voice explanation, to travel services, and more. In terms of intelligent consultation and evaluation, it provides passengers with convenient public tourism services such as tickets, travel, accommodation, purchase, appointments, and inquiries. However, the content with the lowest evaluation by tourists is the advanced AI (artificial intelligence) and VR (virtual reality) services, with a score of only 3.36, indicating that the scenic area can be further strengthened in terms of information promotion and intelligence. Internet + technology can be used to make it practical. Improve the availability and convenience of information for tourists.

In terms of tourism convenience and services, tourists' evaluation is 3.5, ranking second from the bottom. Tourists don't know enough about the city's tourism volunteer service system (3.55) and tourism benefits policies (3.43). The investigation and interview found that the main problem is the uneven distribution of public welfare volunteer services. For example, the Dujiangyan Civilized Tourism Volunteer Service Team mainly conducts volunteer services in its popular scenic spots such as Dujiangyan Water Conservancy Project and Qingcheng Mountain Scenic Area, while for some relatively small tourist attractions. There are few volunteer service teams in scenic spots, so it is necessary to improve the allocation of tourism volunteer services in individual scenic spots. In terms of tourism benefits, there are fewer discounts on tickets and tourist activities in various scenic spots in the city. In addition to discounts for specific groups at specific time periods, such as Teacher's Day and Children's Day, there are relatively few discount activities for the general public.

In terms of tourism public safety services, tourists have poor evaluations of safety notification forecasts (3.44), complete emergency rescue facilities (3.52), etc. The main reason is that tourists have fewer channels to understand the safety rescue system of the scenic area, except for some basic ones. Safety signs or equipment, etc., have little knowledge of relevant safety policies, measures, and early warning and reminders, which shows that the government's information promotion and publication in tourism safety assistance needs to be strengthened, and communication channels with tourists should be expanded.

In terms of convenient travel and transportation services, the total score is 3.75 . During the field visits, the author found that the city has developed roads to major tourist attractions, sufficient refueling points along the way, and convenient parking spots. Only the Dujiangyan Water Conservancy Project Scenic Area and Qingcheng Mountain Scenic Area may be regarded as excellent summer resorts in summer. In some seasons, tourists will surge, leading to congestion. But on the whole, tourists are more recognized by its public transportation service facilities.

In terms of tourist rights protection, the total score is 3.6. It shows that the protection of consumer rights and the supervision of the corresponding service quality are more in line with tourists' psychological expectations, but some tourists still report that some prices are high and environmental protection lacks effective supervision; in terms of handling complaints and opinions from tourists, nearly half of them The tourist evaluation is "fair", which means that the relevant travel service personnel can respond quickly to the complaints of passengers, but the satisfaction with the processing results is average, which means that the processing methods and quality need to be further regulated.

\subsection{Multiple Linear Regression}

Using multiple linear regression, with the help of spss software, to analyze the relationship between the overall evaluation of Dujiangyan's global tourism public service system and the evaluation of each subsystem. Assuming that the overall evaluation is $\mathrm{Y}$, tourism public information service (X1), tourism convenience and benefit service (X2), tourism public safety service (X3), tourism convenient transportation service (X4), tourist rights protection service (X5), regression formula hypothesis for:

\section{$\mathrm{Y}=\mathrm{b} 0+\mathrm{b} 1 \mathrm{X} 1+\mathrm{b} 2 \mathrm{X} 2+\mathrm{b} 3 \mathrm{X} 3+\mathrm{b} 4 \mathrm{X} 4+\mathrm{b} 5 \mathrm{X} 5$.}

The analysis results show that the model fit $\mathrm{R}$ is 0.564 , indicating that the model fits well, and the model significance $\mathrm{p}$ value is $0.015^{*}$, which is less than 0.05 , indicating that the model is significant. 
Table 2. Regression analysis coefficients of tourism public service evaluation system

\begin{tabular}{|l|l|l|l|l|l|}
\hline Model & B & Std.Error & Beta & t & \multicolumn{1}{c|}{ Sig. } \\
\hline Constant & \multicolumn{1}{|c|}{0.182} & \multicolumn{2}{|c|}{$031^{*}$} \\
\hline X1 & 0.537 & 0.245 & 0.031 & 5.132 & $0.044^{*}$ \\
& & & & & \\
\hline X2 & 0.127 & 0.145 & 0.012 & 3.222 & $0.037^{*}$ \\
\hline X3 & 0.121 & 0.153 & 0.004 & 2.141 & $0.042^{*}$ \\
\hline X4 & 0.359 & 0.227 & 0.048 & 3.173 & $0.048^{*}$ \\
\hline X5 & 0.303 & 0.246 & 0.045 & 5.029 & $0.028^{*}$ \\
\hline
\end{tabular}

From the regression analysis coefficients in Table 2 , we can see that the regression model formula under nonstandardized coefficients is:

$$
\mathrm{Y}=0.182+0.537 \mathrm{X} 1+0.127 \mathrm{X} 2+0.121 \mathrm{X} 3+0.359 \mathrm{X} 4+0 \text {. }
$$
$303 \times 5$

From this model, it can be seen that the three subsystems of tourism public information service, tourism public convenient transportation, and tourist rights protection service have a greater impact on the overall evaluation of the system, while the two subsystems of tourism convenience and public safety services have a smaller impact on the overall evaluation.

\section{SUGGESTIONS ON IMPROVING DUJIANGYAN'S GLOBAL TOURISM PUBLIC SERVICES}

\subsection{Improve Public Information Services, Point to Area, and Further Develop and Publicize Surrounding Supporting Scenic Spots}

Through the feedback of tourists, it is found that Dujiangyan's tourism products are relatively single, mostly sightseeing products, and experience interactive tourism products are less, resulting in short stay time of tourists and poor experience of tourists; plus tourists It reflects that I know more about Dujiangyan's popular scenic spots, such as Dujiangyan Water Conservancy Project and Qingcheng Mountain. It is also these scenic spots that go to more, but little is known about some niche scenic spots in Dujiangyan. Therefore, some people suggest to give full play to the leading role of various popular scenic spots, increase publicity for the development and construction of surrounding supporting scenic spots, develop diversified tourism products, and enhance tourists' sense of travel experience.

Specifically, we can vigorously explore the cultural resources of Dujiangyan, actively play the role of the market, develop characteristic tourism products, and fully integrate the driving force of the five scenic spots of Dujiangyan Water Conservancy Project Scenic Area, Qingcheng Scenic Area, Guanxian Ancient City Scenic Area, Hongkou Scenic Area, and Rural Tourism Scenic Area. It can be widely promoted through multiple network channels, such as Douyin, Weibo, etc., using short videos, dynamic pictures, etc., to enhance the popularity of surrounding scenic spots while improving the tourist public services of the scenic spots.

Increase the construction of $5 \mathrm{G}$ base stations and expand the coverage of free WIFI to actively respond to the situation that some tourists have reported that they have gone to parts of the scenic spot and there is no signal from their mobile phones. Dujiangyan can introduce intelligent means, such as the development and construction of related content APP, the use of virtual reality technology, stereo projection technology, etc. to provide tourist interpretation services for tourists. And make full use of mobile terminals, LBS location service technology, Internet of Things technology and other means to actively push the software download of the surrounding public tourism information functions to facilitate the convenient and efficient acquisition of relevant tourism information by tourists.

\subsection{Strengthen the Construction of Smart Tourism and Improve Services for the People and the People}

In order to solve the phenomenon that tourists have low satisfaction with volunteer services and tourism preferential policies in the convenience and benefits of the people. First, strengthen the construction and training of tourism public welfare volunteer teams to form a professional team of volunteers who can provide outdoor first aid, emergency rescue, tourism consulting and other services. Secondly, the establishment of a government-university cooperation mechanism for the tourism industry can strengthen cooperation with Chengdu universities near the scenic spot, such as Sichuan Agricultural University Dujiangyan Campus, Sichuan International Studies University Chengdu University, Chengdu Neusoft College and other universities to establish a team of college student tourism volunteers team. Finally, appropriately expand tourism preferences. Preferential activities can be carried out at different times of the year, and appropriate ticket discount activities can be provided according to different tourist attractions, or cultural experience activities can be carried out. In addition to price reduction activities for special groups of people, scenic spots are encouraged to carry out a number of publicbenefit policies for public tourists. 
In addition, many tourists have reported that although resting spots are set up in the scenic area, they are a bit far apart. Sometimes it takes a long time to get some water. If there is a sudden rain, it will greatly reduce the tourists' Satisfaction of tourism, so in order to increase the convenience and comfort of tourists traveling, you can make full use of shared equipment and establish corresponding demand-sharing service stations, such as shared umbrellas, power banks, and direct drinking water; you can also develop toilet apps to solve scenic spots The difficulty of finding a toilet is that tourists use the APP to find the nearest toilet and the current usage of the toilet. At the same time, a selfhelp button is set in the APP to solve unexpected safety problems with one click.

\subsection{People-oriented, Strengthen the Publicity of Safety Knowledge, and Improve Tourism Public Safety services}

In terms of tourism public safety services, due to tourists' lack of understanding of the tourism safety service system and insufficient government publicity in this area, tourists' evaluations of safety notices and forecasts are timely and accurate, and emergency rescue facilities are complete. First of all, travel agencies and scenic spots should strengthen the popularization of safety knowledge for tourist teams, further improve and publicize the relevant safety regulations of scenic spots, and the importance of purchasing travel insurance, and enhance tourists' awareness of self-safety protection. At the same time, strengthen the safety training of relevant practitioners in scenic spots to provide tourists with high-quality and guaranteed safety services. Secondly, make full use of the Internet big data platform to monitor passenger flow, prevent the occurrence of stampede incidents, and issue some risk warning notices through multi-departmental cooperation and use multiplatforms to effectively protect the lives of tourists. Finally, establish and improve the emergency plan system to effectively deal with emergencies and emergencies.

\subsection{Improve the Self-driving Service System and Guide Signs of Public Transportation}

According to statistics, most of the tourists in Dujiangyan Scenic Area are from Sichuan Province and neighboring provinces and cities. The main way of travel is self-driving vacation. Therefore, with the increasing popularity of self-driving tours, in response to market demand, develop special self-driving tourist routes, continuously improve the construction of selfdriving highway hubs and service supporting facilities, and plan self-driving tourist camps in major scenic spots. Second, create a reasonably shared urban space. The development of global tourism is inseparable from the consideration of reasonable spatial planning. This requires that the city needs to consider both the tourist needs of tourists and the residential needs of residents in the process of tourism planning and construction of tourist facilities, because the tourism industry is embedded in the living area. It involves the consideration of the residents' happiness in life. Therefore, in the process of tourism infrastructure construction, adhere to the bottom line of ecology and development, and promote a reasonable spatial layout.

According to the survey results, the more choices of travel methods for tourists are self-guided tours and self-driving tours. In order to meet the diverse needs of tourists and increase the experiential tourism of tourists, on the one hand, for tourist groups such as trekking tourists, a trekking system along mountain trails will be built, tent camping sites will be built near each station, and camping facilities (such as setting up camping pallets) and Simple recreational facilities. On the other hand, for self-driving tourists and cycling tourists, combined with the theme and culture of the scenic spot, we will build camps with different themes, and set up comprehensive service areas, camping areas, RV parking areas, forest bars, barbecue areas, self-driving car parking areas, log cabin camps, The outdoor expansion activity area provides outdoor leisure service facilities for self-driving tourists, RV campers and camping enthusiasts who do not have RVs.

According to field research, there are many road signs missing on the road leading to Dujiangyan Scenic Area. Improve the tourism guidance marking system outside the scenic area. Set up external signs at through train stations in major scenic spots in Chengdu, such as the main arterial roads leading to Qingcheng Mountain, Dujiangyan Water Conservancy Project and other key scenic spots; at major traffic stations, Chengdu North Station, Chengdu Ximen Station, Chengdu Chadianzi Passenger Transport Station, Chengdu Shuangliu Airport, etc. Guide boards are set up at the site to allow visitors to intuitively feel the overall distribution of Dujiangyan's tourism resources.

\subsection{Strengthen the Supervision of Environmental Sanitation and Price Mechanisms to Effectively Protect the Legitimate Rights and Interests of Tourists}

First of all, multiple complaint channels should be opened. In addition to the tourism complaint service hotline, Dujiangyan has also opened a comprehensive tourism complaint reporting platform such as online messages and offline visits. You can also continue to broaden the complaint channels and use mobile terminals such as WeChat or APP to handle related complaints or opinions anytime and anywhere. You can also paste a QR code that can be directly complained to at the corresponding location of the scenic spot, so that the staff can find the problem in time and solve it. 
The second is to ensure the timeliness and rationality of complaints being resolved. In addition to realizing 24-hour registration and accepting visitors' opinions, the professionalism and courtesy of the staff should also be enhanced. Finally, the tourists' complaints are handled, answered and investigated for return visits, and the processing results are uploaded to the travel complaint reporting platform to facilitate the tourists to grasp the progress of the incident.

Environmental sanitation is the basis for tourists to perceive public tourism services. Especially in recent years, Dujiangyan has made great efforts to create rural tourism. A good local environment and cultural heritage can enhance tourists' sense of travel experience. Therefore, in the scenic area, it is necessary to strengthen the education of garbage classification for tourists, increase tourist toilets, and increase classified garbage bins.

Through the service experience of some tourists to tourism public service personnel, they have reflected the phenomenon that some staff have a bad service attitude, so it is necessary to increase the management of service personnel. For Dujiangyan Scenic Area, a series of advantages can be introduced through the introduction of talents. Support policies to improve the quality of tourism service personnel. For example, through schoolenterprise cooperation training and other forms, the ability of existing tourism service personnel can be improved, and spiritual incentives can also be strengthened, such as the establishment of awards and bonuses for special tourism service personnel.

In addition, some tourists also reported that the prices of Dujiangyan scenic spots are a bit high. Although this is a common phenomenon in tourist attractions, it is necessary to prevent illegal and unreasonable prices. Therefore, it is necessary to supervise the whole process of tourism services and formulate a measurement of tourism. The quantitative evaluation index system of public service quality uses detailed standards to regulate all aspects involved in the provision of tourism public services. For example, in response to the problem of high prices, it is necessary to formulate travel accommodation, food and other consumer goods to meet certain safety and quality standards, and to monitor the quality of related services throughout the process to effectively protect the legitimate rights and interests of tourists.

\section{CONCLUSIONS}

Under the background of vigorous global tourism market, the number of tourists and tourism income have been increasing. At the same time, the demand for tourists and the tourism market are also changing constantly. How to establish a more diverse, flexible, autonomous and complete tourism public service system to improve tourist satisfaction has become more a concern. Taking Dujiangyan City as the empirical research object, the paper constructs the evaluation index system of public service, and evaluates its tourism public services through questionnaire surveys, interviews and multiple regression methods. It is found that Dujiangyan City Global tourism public services have various problems, such as low level of intelligence in information publicity in scenic spots, less tourismbenefiting activities, unbalanced distribution of voluntary services, fewer channels for tourists to understand public safety services, high prices in scenic spots, and insufficient efforts to protect the ecological environment. Finally, according to the evaluation results, corresponding improvement measures are proposed as follows: increasing the development of scenic spots, building smart tourism, improving public transportation services, improving the public safety service system, and strengthening the protection of tourists' rights and interests.

\section{REFERENCES}

[1] Li Bo. Innovation of public service capacity improvement path under the concept of global tourism-taking the construction of Guiyang Global Tourism Demonstration Zone as an example [J]. West China Tourism, 2020(05): 48-51. (In Chinese)

[2] Shen Shiyi, Xia Hanjun. The improvement of tourism public service quality under the background of global tourism-Taking Changdehe Street as an example [J]. Western Tourism, 2020(05):23-28. (In Chinese)

[3] Cao Hui, Li Zhengxiong. Research review of county economic development under the background of global tourism [J]. China Market, 2018(19):14-16. (In Chinese)

[4] Cheng Daopin, Cheng Jinhe, Xiao Tingting. Research on the Structural Relationship between Tourism Public Service System and Tourism Destination Satisfaction-Taking Guilin National Tourism Comprehensive Reform Pilot Area as an example [J]. Human Geography, 2011, 26(05):111116. (In Chinese)

[5] Chen Yizi. Research on Yichun City's Global Tourism Public Service Based on Tourist Satisfaction [D]. Northeast Forestry University Administration, 2019. (In Chinese)

[6] Hou Xiaomin. Construction and Empirical Research on the Evaluation Index System of Tourism Public Service under Global Tourism [D]. Inner Mongolia University of Finance and Economics, 2017. (In Chinese) 
[7] Luo Xiaojun, Zhang Zongshu, Su Bingjie. Research on Deyang Tourism Public Service Supply System Tourist Satisfaction under the Background of Chengde's Urbanization [J]. Equipment Manufacturing and Education, 2020, 34(02): 58-62+76. (In Chinese)

[8] Xu Fuying, Liu Tao. Review and Prospect of Domestic Tourism Public Service Research [J]. Journal of Shandong Institute of Business and Technology, 2020, 34(04): 37-46. (In Chinese)

[9] Zhang Jucheng, Li Yiming, Cheng Ruxia. A review of smart tourism research at home and abroad [J]. Tourism Guide, 2020, 4(05): 79-96. (In Chinese)

[10] Li Huajun. Research on the improvement of Wuyishan's global tourism public service based on satisfaction [D]. Huaqiao University, 2020. (In Chinese)

[11] Dai Xuefeng, Chen Yao. Reformation and practice exploration of the global tourism demonstration zone [J]. Tourism Tribune, 2020, 35(02): 3-5. (In Chinese)

[12] Guan Xiangling. Research on the Existing Problems and Countermeasures of Zhangjiajie Tourism Public Service [D]. Nanjing University of Science and Technology, 2017. (In Chinese)

[13] Zhang Yabin, Wang Zirun, Jin Pingbin. Research on the Construction of Chengdu Tourism Public Service System from the Perspective of Smart Tourism [J]. Modern Business, 2018(05):47-50. (In Chinese)

[14] Zhao Yiqing, Huang Yanling, Luo Shengfeng. Construction of County Public Service System for Industrial Transformation under the Background of Global Tourism [J]. Journal of Guangxi Radio and Television University, 2019, 30(01): 46-51. (In Chinese)

[15] Wang Jiaxin, Zhang Zaisheng. Research on the supply sequence of tourism public services based on the perspective of tourist demand [J]. Guizhou Social Sciences, 2017, (7): 128-133. (In Chinese)

[16] Xiao Tingting, Huang Yanling, Cheng Jinhe. Research on Tourist Satisfaction of Tourism Public Services Based on Factor Analysis-Taking Guilin National Tourism Comprehensive Reform Pilot Area as an example [J]. Journal of Beijing International Studies University, 2011, 33(01): 7682. (In Chinese)

[17] Li Jinzao. Contemporary Tourism [M]. Beijing: The Commercial Press, 2018. (In Chinese)
[18] Li Shuang. Tourism public services: connotation, characteristics and classification framework [J]. Theoretical Reference, 2012(09): 36-38. (In Chinese)

[19] Huang Yanling, Luo Shengfeng, Ding Peiyi. Research on the development of tourism public services from the perspective of supply and demand perception: A case study of Guilin National Tourism Comprehensive Reform Pilot Area [J]. Tourism Tribune, 2010, 25(07): 70-76. (In Chinese)

[20] Ye Quanliang, Rong Hao. Research on Tourism Public Service Evaluation Based on Analytic Hierarchy Process [[J]. Journal of Zhongnan University of Economics and Law, 2011, (03): 47 54. (In Chinese)

[21] Yang Jingfeng and Huang Yanling, Construction and Prospects of Tourism Public Services in the Context of Global Tourism-Based on the Quantitative Analysis of Documents Since the New Century. Journal of Sichuan Institute of Tourism, 2019(03): 83-88. (In Chinese) 